\title{
First experience with the new high-frequency femtosecond laser system (LDV Z8) for cataract surgery
}

This article was published in the following Dove Press journal:

Clinical Ophthalmology

8 December 2014

Number of times this article has been viewed

\author{
Bojan Pajic ${ }^{1-3}$ \\ Iraklis Vastardis ${ }^{1,2}$ \\ Zisis Gatzioufas' \\ Brigitte Pajic-Eggspuehler' \\ 'Swiss Eye Research Foundation, Eye \\ Clinic ORASIS, Reinach, Switzerland; \\ ${ }^{2}$ Eye Hospital VIDAR-ORASIS Swiss, \\ Department of Physics, Faculty of \\ Sciences, University of Novi Sad, \\ Novi Sad, Serbia; ${ }^{3}$ Medical Faculty, \\ Military Medical Academy, University \\ of Defense, Belgrade, Serbia
}

Background: The purpose of this work is to report our experience using the new Z8 laser system for femtosecond laser-assisted cataract surgery (FLACS) and to provide a sample of the performance and safety results using this new technology.

Methods: This prospective observational study was performed at the Swiss Eye Research Foundation, Eye Clinic ORASIS, Reinach, Switzerland. Fourteen patients were subjected to unilateral FLACS. Capsulotomy and lens fragmentation were performed with the aid of the LDV Z8 femtosecond laser system. Ease of phacoemulsification (on a 4-point scale), completeness of capsulotomy (on a 10-point scale), time for preparation of femtosecond laser (minutes), effective phacoemulsification time (seconds), total duration of surgery (minutes), and safety of the procedure were evaluated.

Results: Ease of fragmentation and completeness of capsulotomy were estimated at 3.9 and 9.9 , respectively. The preparation time for femtosecond was $3.6 \pm 0.7$ minutes, effective phacoemulsification time was $2.5 \pm 3.1$ seconds, and total duration of the FLACS procedure was $16.3 \pm 4.5$ minutes. No major complications were observed. Approximately $42 \%$ of all patients (6/14) showed Descemet's folds directly postoperatively.

Conclusion: FLACS with the LDV Z8 system was characterized by complete capsulotomy and highly effective and reproducible lens fragmentation. The safety of the procedure was very good as perceived by the surgeon operating in this observational case series. The cost to benefit ratio should be further debated by assessing the results of a major prospective study, which is required for valid evaluation of the efficiency and safety of the LDV Z8 laser system and of FLACS in general.

Keywords: femtosecond laser, cataract surgery, effective phacoemulsification time, complications

\section{Introduction}

Femtosecond laser technology has been widely used in various refractive surgery procedures, providing enhanced efficiency and safety in corneal refractive surgery. Recently, femtosecond laser application in cataract surgery has been gaining increasing interest, given that use of premium intraocular lenses and higher patient expectations amplify the necessity for more predictable and accurate refractive outcomes, as well as maximum safety. Femtosecond laser systems have been used during cataract surgery for performing anterior capsulotomy, lens fragmentation, and clear corneal incisions. Numerous studies have reported the possible advantages of femtosecond laser over conventional phacoemulsification cataract surgery.

Available data have shown that capsulotomies created using the femtosecond laser are more accurate in size than those created by manual continuous
Correspondence: Bojan Pajic Swiss Eye Research Foundation, Eye Clinic ORASIS, Titlisstrasse 44, Reinach 5734, Switzerland Tel +4I6 27656080 Email bpajic@datacomm.ch 
curvilinear capsulorhexis and that laser lens fragmentation is accompanied by a significantly decreased phacoemulsification power. ${ }^{1-5}$ Moreover, clear corneal incisions performed by femtosecond laser were superior to conventional corneal incisions in terms of tunnel morphology and tissue damage, and they did not significantly increase high-order aberrations postoperatively. ${ }^{6-8}$ Femtosecond laser-assisted cataract surgery (FLACS) is generally safe with a low overall complication rate and provides excellent clinical outcomes, which improve significantly with increasing surgeon experience during the learning curve of this technique. ${ }^{9,10}$

The Femto LDV Z8 (Ziemer Ophthalmic Systems AG, Port, Switzerland) is a new high frequency femtosecond laser system, which enables the whole spectrum of corneal-refractive surgery as well as cataract surgery. It has a powerful laser source allowing the resection of a larger target volume with adjustable pulse energy (nJ) according to cataract grade and a very high repetition rate in the $\mathrm{MHz}$ range. It uses a new liquid-patient interface that prevents posterior corneal folds, guaranteeing good transmission of the laser beam, with only a minimal intraocular pressure increase during surgery. Finally, integrated high-definition ocular coherence tomography allows identification of the precise location of the ocular surfaces intraoperatively.

In this small case series, we report our experience in terms of safety and performance perceived by the surgeon and provide prospective results for 14 eyes by operating for the first time with the prototype Z8 laser system for FLACS.

\section{Patients and methods}

This was a prospective observational case series study that included patients with nuclear sclerosis who underwent unilateral FLACS. The inclusion criteria for participation were: age older than 50 years, ability to cooperate with the docking system requirements for femtosecond laser, clear corneal media, full pupil dilation attainable $(>7 \mathrm{~mm})$, and ability to return for scheduled follow-up examinations. Exclusion criteria were: a maximum K-value more than $58 \mathrm{D}$, minimal K-value less than $37 \mathrm{D}$, corneal disease or pathology, such as corneal scarring or opacity, a poorly dilating pupil, lens/ zonular instability, manifest glaucoma, pseudoexfoliation, previous intraocular or corneal surgery of any type, connective tissue weakness, blindness in one eye, age-related macular degeneration, immunological disease, anterior chamber depth less than $1.5 \mathrm{~mm}$ or more than $4.8 \mathrm{~mm}$ as measured from the corneal endothelium, serious psychiatric illness such as dementia or schizophrenia, psychiatric hospitalization in the past 2 years, developmental disability or cognitive impairment, concurrent participation in another clinical ophthalmology study, involvement in litigation and/ or receiving disability benefits related to the parameters of the study, and age younger than 50 years.

An experienced surgeon (BP) performed all the procedures at Orasis Eye Clinic (Reinach AG, Switzerland) in May 2014. The Kantonal Ethikskomission local ethics committee approved the study. FLACS and lens fragmentation was performed in all 14 patients accounted using the Z8 laser system, which has received US Food and Drug Administration clearance as well as $\mathrm{CE}$ accreditation for laser procedures.

All surgeries were performed under topical anesthesia (proparacaine hydrochloride eye drops). The procedure is shown in Figure 1. Pupil dilation during surgery was achieved by combined use of phenylephrine and tropicamide eye drops. Initially, a disposable suction ring was applied to the eye, with careful centration over the limbus (Figure 1A). After the suction ring was filled with balanced salt solution in order to create a fluid-filled interface, the mobile arm of the laser system was docked over the corneal apex (Figure 1B). The integrated ocular coherence tomography system imaged the ocular structures, and treatment parameters were determined in a customized manner using the laser platform settings wizard. Laser treatment started with lens fragmentation (an eight-piece pie-cut pattern) followed by an anterior capsulotomy (5.0 mm diameter; Figure 1C).

After removal of the anterior capsule (Figure 1D), hydrodissection and nuclear splitting (Figure 1E), bimanual phacoemulsification was performed using the Catharex 3 system (Oertli Instrumente AG, Berneck, Switzerland, Figure 1F). Finally, bimanual irrigation/aspiration of the residual cortex was performed followed by posterior capsule polishing (Figure 1G). All intraocular lenses were placed in the capsular bag (Figure $1 \mathrm{H}$ and I) without complications.

The patients were scheduled for postoperative examination at one day, 2 weeks, and one, 2, and 3 months after surgery. The main measures evaluated in this study were preparation time for femtosecond laser (minutes), effective phacoemulsification time (EPT, seconds), total duration of surgery (minutes), ease of phacoemulsification (on a 4-point scale), completeness of capsulotomy and ease of capsule button removal (on a 10-point scale), and complications. Cataract severity was graded according to nuclear opalescence on the Lens Opacities Classification System III. ${ }^{11}$ Only grade 2 and 3 cataracts were included in the study.

The surgeon rated the ease of capsule button removal on a scale from 1 to 10 , with 1 denoting an incomplete capsulotomy requiring a full or partial manual curvilinear capsulorhexis and 10 denoting a free-floating capsule button. ${ }^{12}$ All grading systems were selected to reflect the surgeon's 

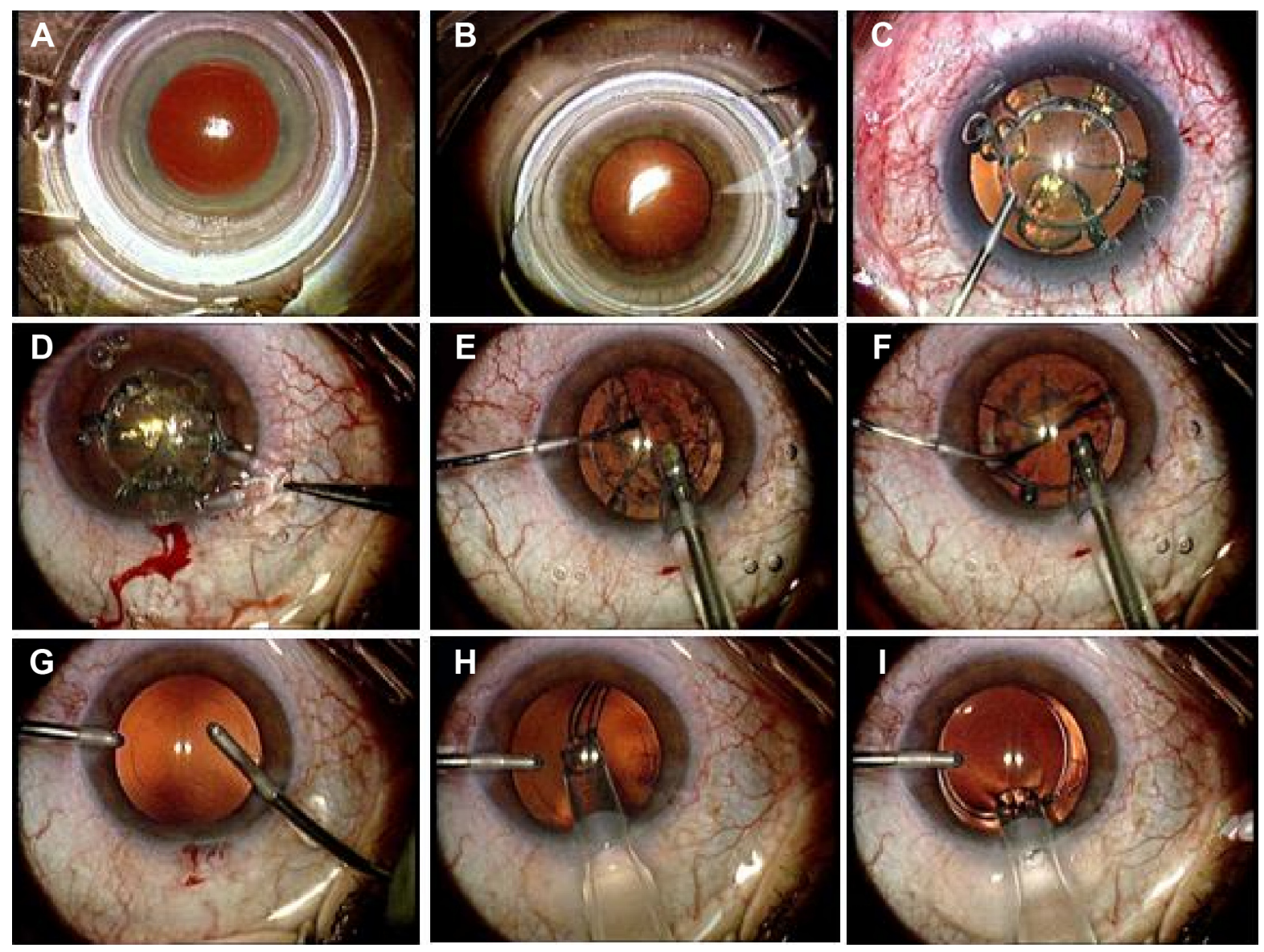

Figure I Femtosecond laser-assisted cataract surgery with the LDV Z8 system.

Notes: Application of suction ring with careful centration over the limbus (A). Docking of the laser system over the corneal apex (B). Completion of lens fragmentation (pie-cut pattern) followed by an anterior capsulotomy (5.0 mm diameter) (C). Removal of the anterior capsule (D). Hydrodissection and nuclear splitting (E). Bimanual phacoemulsification performed using the Oertli Catharex 3 system (F). Bimanual irrigation/aspiration of the residual cortex and posterior capsule (G). Placement of the intraocular lens in the capsular bag $(\mathbf{H}, \mathbf{I})$.

actual experience of performing FLACS with a prototype laser system platform.

Statistical analysis was performed for descriptive demographic data and the clinical measures used in the study. Oneway analysis of variance was used to compare the means of the total FLACS time in different operation sessions during the learning curve of the procedure. A $P$-value less than 0.05 was considered to be statistically significant. The statistical analysis was performed using MedCalc version 12.7.0 software.

\section{Results}

A total of 14 patients (four males and ten females) were enrolled in the study. The mean patient age was $73.5 \pm 10.6$ years (70.2 \pm 8.3 years for males and $74.9 \pm 11.3$ years for females). Unilateral FLACS was performed in eight right eyes and six left eyes. Eight patients had grade 2 cataract and six patients had grade 3 cataract according to the Lens Opacities Classification System III.

The femtosecond laser preparation time before each operation was $3.6 \pm 0.7$ minutes. Effective phacoemulsification time was $2.5 \pm 3.1$ seconds. The total duration of FLACS was $16.3 \pm 4.5$ minutes. The total duration of the procedure for the different phases of the learning curve was $21.9 \pm 1.8$ minutes for the first surgery session (three patients), 16.0 \pm 2.7 minutes for the second session (six patients) and 12.5 \pm 1.1 minutes for the third session (five patients, Figure 2). Ease of fragmentation was 3.9 and completeness of capsulotomy was 9.9 , as evaluated by the surgeon. No major complications, such as anterior capsule tears, posterior capsule tears, or dropped nuclei occurred during the study. Moreover, none of the patients developed subconjunctival hemorrhage postoperatively. Finally, $42 \%$ of the patients (6/14) showed Descemet's folds directly postoperatively.

\section{Discussion}

Femtosecond lasers were first introduced for laser in situ keratomileusis, where they enable more precise and predictable flaps to be performed when compared with the traditional microkeratome. ${ }^{13}$ They have also been used successfully to create corneal pockets for implantation of intracorneal 


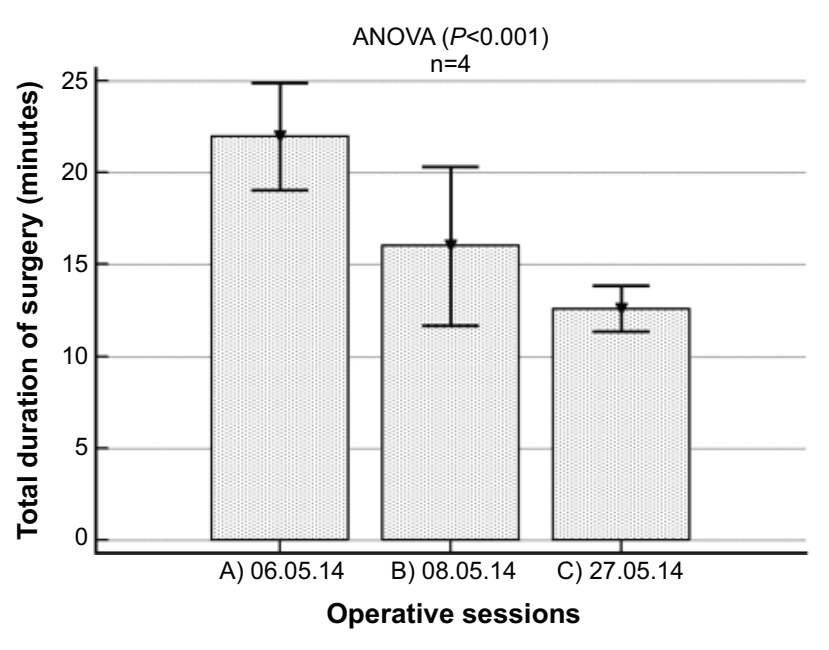

Figure 2 Total duration of femtosecond laser-assisted cataract surgery with the Z8 laser system in three different time sessions during the learning curve for this procedure.

Abbreviation: ANOVA, one-way analysis of variance.

ring segments, arcuate keratotomies for correction of high astigmatism, and in keratoplasty, with numerous performance studies showing them to be safe and efficient. ${ }^{14-16}$ FLACS is the most recent application of femtosecond laser technology in ophthalmic surgery and appears to be a safe, efficient, and reproducible procedure. ${ }^{17}$ The most important features of FLACS include the creation of precise, perfectly centered anterior capsulotomies and effective lens fragmentation. Lens fragmentation by femtosecond laser offers many potential advantages over manual surgery, as pretreatment may allow for reduced instrumentation, movement, and EPT during cataract removal, presumably resulting in increased safety.

Lower EPT is also associated with less vacuum, fluid, and intraocular manipulation during surgery, leading to improved clinical outcomes secondary to a lower risk of injury to the capsule, iris, and corneal endothelium, along with reduced endothelial cell loss, postoperative inflammation, and corneal edema. Indeed, results from previous studies have documented that capsulotomies created using the femtosecond laser are more accurate in size than those created by manual continuous curvilinear capsulorhexis ${ }^{2,4}$ and that laser-assisted lens fragmentation is accompanied by significantly decreased phacoemulsification power. ${ }^{3,18}$

In this case series, we used the high frequency femtosecond LDV Z8 laser system, which facilitates visualization of the anterior corneal surface and posterior lens capsule regardless of cataract grade. The fluid-filled interface does not lead to formation of marked corneal folds, so delivers uninterrupted laser treatment. ${ }^{19}$ These features enabled precise and complete removal of the capsule button. Indeed, 13 of 14 capsule buttons were free floating (score 10) and one required only minimum effort for removal (score 9). Ease of fragmentation as perceived by the surgeon was excellent (3.9), as reported in other studies. EPT was low, as expected, since with femtosecond laser segmentation and fragmentation, the required phacoemulsification power decreases markedly. ${ }^{3,5,20}$ Total duration of surgery decreased significantly during the learning curve period (all $P<0.05$ ).

Regarding the safety of the procedure, it has been reported that radial anterior capsule tears, posterior capsule tears, and dropped nuclei are major complications of FLACS. ${ }^{9}$ In our study, we did not observe any major complications, indicating that meticulous preparation of the femtosecond laser settings could provide high levels of safety during the procedure. No subconjunctival hemorrhages were observed, and approximately $42 \%$ of patients showed Descemet's folds postoperatively. The latter was probably the result of the learning curve when operating with a new technology and due to the change in operation method.

In conclusion, FLACS with the Z8 system in this small sample of eyes appeared to facilitate complete and precise capsulotomy, together with highly effective and reproducible lens fragmentation. The safety level of the procedure was very good as perceived by the surgeon, and the time-consuming adjustments on the femtosecond-laser setting wizard, although relatively high in the early period, were markedly improved during the learning curve for this method. Nevertheless, further studies with higher patient volumes are required for valid investigation of efficiency and safety, and to assess the cost-benefit ratio of the emerging FLACS.

\section{Disclosure}

The authors have no proprietary interest in any of the products or procedures mentioned in this paper. The authors report no conflicts of interest in this work.

\section{References}

1. Nagy ZZ, Kranitz K, Takacs AI, Mihaltz K, Kovacs I, Knorz MC. Comparison of intraocular lens decentration parameters after femtosecond and manual capsulotomies. J Refract Surg. 2011;27:564-569.

2. Kranitz K, Takacs A, Mihaltz K, Kovacs I, Knorz MC, Nagy ZZ. Femtosecond laser capsulotomy and manual continuous curvilinear capsulorrhexis parameters and their effects on intraocular lens centration. J Refract Surg. 2011;27:558-563.

3. Conrad-Hengerer I, Hengerer FH, Schultz T, Dick HB. Effect of femtosecond laser fragmentation on effective phacoemulsification time in cataract surgery. J Refract Surg. 2012;28:879-883.

4. Friedman NJ, Palanker DV, Schuele G, et al. Femtosecond laser capsulotomy. J Cataract Refract Surg. 2011;37:1189-1198.

5. Abell RG, Kerr NM, Vote BJ. Toward zero effective phacoemulsification time using femtosecond laser pretreatment. Ophthalmology. 2013;120:942-948. 
6. Grewal DS, Basti S. Comparison of morphologic features of clear corneal incisions created with a femtosecond laser or a keratome. $J$ Cataract Refract Surg. 2014;40:521-530.

7. Alió JL, Abdou AA, Soria F, et al. Femtosecond laser cataract incision morphology and corneal higher-order aberration analysis. $J$ Refract Surg. 2013;29:590-595.

8. Mastropasqua L, Toto L, Mastropasqua A, et al. Femtosecond laser versus manual clear corneal incision in cataract surgery. J Refract Surg. 2014; 30:27-33.

9. Roberts TV, Lawless M, Bali SJ, Hodge C, Sutton G. Surgical outcomes and safety of femtosecond laser cataract surgery: a prospective study of 1500 consecutive cases. Ophthalmology. 2013;120:227-233.

10. Nagy ZZ, Takacs AI, Filkorn T, et al. Complications of femtosecond laser-assisted cataract surgery. J Cataract Refract Surg. 2014;40: 29-36.

11. Chylack LT Jr, Wolfe JK, Singer DM, et al; the Longitudinal Study of Cataract Study Group. The Lens Opacities Classification System III. Arch Ophthalmol. 1993;111:831-836.

12. Tackman RN, Kuri JV, Nichamin LD, Edwards K. Anterior capsulotomy with an ultrashort-pulse laser. J Cataract Refract Surg. 2011; 37:819-824.

13. Santhiago MR, Kara-Junior N, Waring GO 4th. Microkeratome versus femtosecond flaps: accuracy and complications. Curr Opin Ophthalmol. 2014;25:270-274.

14. Lisa C, García-Fernández M, Madrid-Costa D, Torquetti L, Merayo-Lloves J, Alfonso JF. Femtosecond laser-assisted intrastromal corneal ring segment implantation for high astigmatism correction after penetrating keratoplasty. J Cataract Refract Surg. 2013; 39:1660-1667.
15. Birnbaum F, Wiggermann A, Maier PC, Böhringer D, Reinhard T. Clinical results of 123 femtosecond laser-assisted penetrating keratoplasties. Graefes Arch Clin Exp Ophthalmol. 2013;251:95-103.

16. Nubile M, Carpineto P, Lanzini M, et al. Femtosecond laser arcuate keratotomy for the correction of high astigmatism after keratoplasty. Ophthalmology. 2009;116:1083-1092.

17. Donaldson KE, Braga-Mele R, Cabot F, et al; ASCRS Refractive Cataract Surgery Subcommittee. Femtosecond laser-assisted cataract surgery. J Cataract Refract Surg. 2013;39:1753-1763.

18. Reddy KP, Kandulla J, Auffarth GU. Effectiveness and safety of femtosecond laser-assisted lens fragmentation and anterior capsulotomy versus the manual technique in cataract surgery. $J$ Cataract Refract Surg. 2013;39:1297-1306.

19. Talamo JH, Gooding P, Angeley D, et al. Optical patient interface in femtosecond laser-assisted cataract surgery: contact corneal applanation versus liquid immersion. J Cataract Refract Surg. 2013;39:501-510.

20. Conrad-Hengerer I, Hengerer FH, Schultz T, Dick HB. Effect of femtosecond laser fragmentation of the nucleus with different softening grid sizes on effective phaco time in cataract surgery. $J$ Cataract Refract Surg. 2012;38:1888-1894.
Clinical Ophthalmology

\section{Publish your work in this journal}

Clinical Ophthalmology is an international, peer-reviewed journa covering all subspecialties within ophthalmology. Key topics include: Optometry; Visual science; Pharmacology and drug therapy in eye diseases; Basic Sciences; Primary and Secondary eye care; Patien Safety and Quality of Care Improvements. This journal is indexed on

Submit your manuscript here: http://www.dovepress.com/clinical-ophthalmology-journal

\section{Dovepress}

PubMed Central and CAS, and is the official journal of The Society of Clinical Ophthalmology (SCO). The manuscript management system is completely online and includes a very quick and fair peer-review system, which is all easy to use. Visit http://www.dovepress.com/ testimonials.php to read real quotes from published authors. 